\title{
Presentación
}

\section{Una nueva imagen}

\author{
Andrés Alfredo Castrillón Castrillón
}

Forma de citar este artículo en APA:

Castrillón Castrillón, A. A. (2022). Una nueva imagen [Presentación]. Revista Colombiana de Ciencias Sociales, 13(1), 7-9. https://doi. $\operatorname{org} / 10.21501 / 22161201.4219$

Cada nuevo número es una ocasión para ofrecer a los lectores, docentes, estudiantes e investigadores una producción de calidad para para su propio trabajo académico o sus respectivos intereses. Es también una oportunidad para invitarlos a apropiarse de las contribuciones que componen cada volumen para discutir, compartir conocimiento y construir comunidad con los pares tanto locales como nacionales e internacionales de modo que la revista no solo reúna una serie de artículos, sino que siga abriendo la posibilidad para el diálogo. Sirva en esta oportunidad el editorial del profesor Juan Diego Betancur Arias que versa sobre la problemática relación de las ciencias sociales con las actividades de desarrollo técnico, tecnológico e innovador y la producción académica.

El año anterior, la Revista Colombiana de Ciencias Sociales migró a una versión actual de la plataforma que sirve de soporte para todo el proceso editorial y de publicación. Debido a estos trabajos, se presentaron retrasos con el servicio del sistema, agradecemos la paciencia a todos aquellos que tuvieron inconvenientes por esas fechas. Nuestro deseo es mejorar la experiencia de acceso a los artículos y favorecer la agilidad en el proceso para todos a la par que buscamos brindar un sitio más amigable con el público en general.

Con respecto este volumen 13, número 1, abre los artículos de investigación el trabajo titulado "Actitudes sexuales de acuerdo con el nivel de severidad del trauma craneoencefálico" de Dubis Marcela Rincón, María Rocío Acosta Barreto y Diana Milena Fajardo Tejada, cuyo análisis da cuenta de los resultados del estudio realizado con 126 personas con trauma leve, moderado y severo. Por su parte, el texto “¿Son culpables los altos mandos de promover ejecuciones extrajudiciales en Colombia?" de María del Pilar Castillo Valencia y Sebastián Durán aborda el espinoso tema de las muertes ilegítimamente presentadas como bajas en combate por agentes de Estado colombiano bajo la hipótesis de que estos hechos pudieron no ser aislados, sino ordenados. "Violencia intrafamiliar. Un riesgo para el desarrollo de la primera infancia” de María del Carmen Do- 
cal Millán, Paola María Akl Moanack, Leidys Yohana Pérez García y Laura Katherine Sánchez Betancourt, se enfoca en la identificación de formas y tipos de esta violencia que sufren las madres, o en ocasiones las cuidadoras, que pueden repercutir negativamente en los niños y las niñas.

En la investigación "Programas de gobierno colombiano y derechos de las mujeres. ¿Aplica la agenda pública municipal el enfoque de género?” las investigadoras Karen Michelle Cifuentes Cifuentes y Miryam Cristina Fernández Cediel analizaron los documentos públicos de tres municipios del Huila, departamento de Colombia, en relación con los programas para incentivar la participación de las mujeres en los planes de gobierno. El artículo "Learning activities using videos to strengthen intercultural competence in higher education students" de John Cano, Carmen Ricardo Barreto, Jorge Mizuno Haydar y Humberto Llinas Solano tuvo como objetivo determinar las características de las actividades de aprendizaje por medio del uso de videos para promover el desarrollo de la competencia intercultural en los estudiantes de cursos virtuales. En "Narrativas de jóvenes con intentos suicidas: una mirada al cuerpo y la micropolítica" de Sandra Constanza Cañón, Jaime Alberto Carmona Parra y Adriana Arroyo Ortega se examinan las narrativas autobiográficas de estos jóvenes mediante las cuales interpretan las categorías que surgen de estos relatos. El estudio "Responsabilidad social en la red de salud de la Guajira colombiana" de Sayuris Yelind Martínez Salas, Cielo Margarita Rodríguez López y Danny Daniel López Juvinao expone los hallazgos tras el análisis a las encuestas que realizaron en las secretarías de salud de los municipios de Maicao y Uribia. El trabajo "El barrio de Lavapiés (Madrid) visto desde la perspectiva patrimonial. Un lugar de resistencia que representa una oportunidad de mejora social" de María Vanesa Giacomasso y Alicia Castillo Mena se elaboró un diagnóstico de las percepciones sociales del barrio, con el interés de favorecer la apropiación de los habitantes en las decisiones de las propuestas socioeconómicas del patrimonio.

Finalmente, en el artículo "Matemáticas en moldes para la elaboración de estructuras en artesanías de Usiacurí” de Armando Alex Aroca Araújo y Geraldine Santana Ríos se buscó las matemáticas en estos moldes con el propósito de construir ambientes de aprendizaje de esta ciencia en el ámbito escolar.

En cuanto a los artículos de reflexión, iniciamos con "El cuerpo trans: territorio de poder, lugar de resistencia al poder heteronormativo" de María José Martínez Eraso y Heidi Smith Pulido Varón quienes estudiaron la resistencia y subversión del cuerpo trans que se opone a la continua tendencia de normalización del cuerpo. El artículo "El mal en Jean Jacques Rousseau. Sobre el ser humano y el conocimiento de sí” de Víctor Daniel Gómez Montoya y Alexander Hincapié García aborda el tema del mal desde una perspectiva histórica y con el referente de la filosofía moderna a partir de cuatro momentos tomados del pensamiento de Rousseau: vida social, hombre social contrapuestos a estado de naturaleza y hombre natural. Por su parte, el trabajo "Seguridad ampliacionista en el acuerdo de paz de Colombia (2016): seguridad humana, medio ambiente y paz territorial" de William Farfán Moreno expone el análisis reflexivo sobre la implementación 
de derechos sociales y económicos propuestos en las negociaciones entre la FARC y el gobierno de Colombia. Cierra esta sesión el artículo "Del discurso capitalista al neoliberalismo: apuntes sobre la producción del sujeto" de Judith Elena García Manjarrés y Leonardo Rafael Mass Torres en el que se analiza la producción del sujeto inmerso en el capitalismo neoliberal a partir de referentes psicoanalíticos como el lacaniano.

Este número cuenta con un reporte de caso, el artículo "Estratégias participativas para a intervenção em saúde: relato de experiência no pet-saúde graduasus" de Isabel Cristina Belasco y Rafael Andrés Patiño que expone la experiencia de trabajo interdisciplinar sobre el diagnóstico participativo de la situación de salud en la ciudad de Porto Seguro, Brasil, y en el que los investigadores hallaron que uno de los principales problemas en su territorio es la violencia. También se publica un artículo teórico "Representaciones sociales y violencia de género: caso resguardo indígena Cañamomo Lomaprieta, Riosucio Caldas” de Jonnathan Harvey Narváez y Carol Dayana Jurado que hacen un estudio analítico de la violencia contra la mujer en el resguardo indígena del que infieren cuatro momentos representativos de esas situaciones. Cierra este número el texto del profesor Eguzki Urteaga, quien en esta ocasión nos ofrece la reseña del libro de Alain Corbin Terra Incognita. Une histoire de l'ignorance publicado en el 2020. 